\title{
Constraints of health management of commercially cultured high valued fishes
}

\author{
K.M. ABDUL HALIM, MD. NAWSHAD ALI, TANVIR RAHMAN \\ AND MD. ALI REZA FARUK* \\ Department of Aquaculture \\ Bangladesh Agricultural University, Mymensingh 2202, Bangladesh \\ *Email: faruk.mar@bau.edu.bd
}

\begin{abstract}
This study was performed to understand the constraints of health management of commercially cultured high value fishes including gulsha (Mystus cavasius), shing (Heteropneustes fossilis) and koi (Anabas testudineus). One hundred farmers were interviewed through structured questionnaire in Mymensingh and Jashore districts. Most of the farmers practiced polyculture of gulsha and shing with carps and monoculture of koi high densities. All the three species suffered from a number of serious diseases under farming conditions. Most prevalent clinical signs of diseases were ulcerative hemorrhagic lesion, whitish appearance over body surface, ventral and mouth reddening and fin rot. The most susceptible species to disease was shing with a higher average mortality of $43.33 \%$ followed by gulsha $(36.71 \%)$ and koi $(38.76 \%)$. Diagnosis of disease was the single most important constraints of health management followed by lack of farmer's knowledge on fish health and diseases, presence of huge number of poor quality medicine, ineffectiveness and indiscriminate use of such medicine, lack of farmer's ability on application of medicine and absence of qualified fish health adviser. Lack of good quality fish seed, feed and water were identified as the main resource problems associated with fish health management. The study also identified a number of general constraints of farming of high value fish which included low price of fish, higher feed cost, and outbreak of diseases, high land tax, electricity bill and marketing problem. Further studies should focus on the development of strategies for better health management practices for sustainable commercial culture of high value fishes.
\end{abstract}

Keywords: Health management, Disease, High value fishes

\section{Introduction}

Aquaculture has increased the availability of fish for consumption and contributed to improving livelihoods for millions of households in Bangladesh. Currently, Bangladesh is one of the world leading aquaculture producing countries and currently ranked $5^{\text {th }}$ position in global aquaculture production (DoF 2019, FAO 2020). Aquaculture is considered to have the potential of food security in Bangladesh (Jahan et al. 2010). Common aquaculture practices in Bangladesh have mainly been associated with the culture of carps, tilapias, catfishes, climbing perches or koi and shrimp. However, there has been rapid expansion of farming of high value fishes including gulsha ( $M$. cavasius) shing (H.fossilis) and koi (A. testudineus) and particularly in Mymensingh and Jashore districts. These species are designated as high value species and they can benefit fish farmers because of their high productivity, market demand and profitability. They can be cultivated twice a year, giving the farmers an opportunity to increase their earnings. These fishes are cultured mostly as commercial basis by entrepreneurial farmers and contribute about $5 \%$ in pond aquaculture of Bangladesh (DoF 2017).

Like other farming systems, aquaculture is plagued with disease problems resulting from its intensification and commercialization (Bondad-Reantaso et al. 2005). Disease outbreak is 
considered to be a significant constraint to the development of aquaculture sector, causinghuge economic losses per year worldwide (Austin and Austin 2012, Bergh 2007).A global estimate of disease losses to aquaculture is over US\$ 6 billion per annum (World Bank 2014). Fish health management is a term used in aquaculture to describe management practices which are designed to prevent fish disease (Floyd 2005). It is an important issue of commercial aquaculture. Once fish get sick it can be difficult to recover them. Successful fish health management begins with prevention of disease rather than treatment. Prevention of fish disease is accomplished through good water quality management, nutrition, and sanitation. An effective health management program for fish farming needs to cover all levels of aquaculture from the production unit such as ponds as well as entire farm area and the area where the farm operates (Bondad-Renataso et al. 2005). Without this, it is impossible to prevent outbreaks of opportunistic pathogens and diseases.

High value fishes are generally cultured commercially in high stocking densities. As a consequence density associated stress and other husbandry risks greatly increase the threat of infection. Recently, there have been reports of serious disease outbreaks and mortality of high value fishes under farming conditions in Bangladesh. Due to disease and health problem, the productivity and quality of fishes is hampered seriously and farmers are not getting proper return of their investment. Prevention and control of fish diseases in commercial farming condition are a function of proper health management. However, there is lack of information about disease and health management issues of high value fishes. This study aimed to identify constraints of health management and understand overall problems of commercially cultured high value fishes.

\section{Materials and Methods}

The present study focused on commercial fish farmers culturing high value fishes including gulsha, shing and koi in Mymensingh and Jashore districts. Data was collected through questionnaire interview with 100 farmers (50 from each district). A set of preliminary questionnaire was prepared focusing mainly on the general farming information, fish culture practices, stocking density, diseases issues, fish health management constraints and overall problems of farming of high value fishes. The preliminary questionnaire was then tested at field level and based on feedback, the final set questionnaire was developed for data collection.Qualitative data was collected through participatory rural appraisal tools like focus group discussion (FGD) and ten FGD sessions in two districts were conducted. Each group size was between 10 to 14 farmers. The data were tabulated in the computer and raw data were entered into the spread sheet of the Microsoft Office Excel program to analyze. Clinical observation of fish was made on spot and any abnormalities, injury, lesion, infection and other unusual conditions of fish body were recorded.

\section{Results}

Culture strategy and production of high value fishes: Farmers practiced both poly and monoculture of high value fish in the study areas. Average $65 \%$ farmers practiced polyculture, $24 \%$ practiced both polyculture and monoculture and $11 \%$ practiced only monoculture (Table I). Gulsha and shing were mainly cultured with carps in polyculture system. Monoculture was 
mainly performed only with koi. Farmers used to collect fish fry of $0.2-0.5 \mathrm{~g}$ size from local hatchery for culture. Generally, they stocked fish at high densities. The stocking density of koi was found much higher than that of gulsha and shing. Average stocking density of in polyculture system were 192,081 (fry/ha) and 195,497 (fry/ha) for gusha and shing, respectively while it was 557,063 (fry/ha) for koi in monoculture (Table II). The stocking density of gulsha and koi were higher in Jashore than Mymensingh while stocking density of shing was higher in Mymensingh than Jashore (Table II).

Table I. Culture System in the study areas (\%)

\begin{tabular}{lccc}
\hline Culture system & $\begin{array}{c}\text { Mymensingh } \\
\mathrm{n}=50\end{array}$ & $\begin{array}{c}\text { Jashore } \\
\mathrm{n}=50\end{array}$ & Mean $\pm \mathrm{SD}$ \\
\hline Monoculture & 10 & 12 & $11 \pm 1.41$ \\
Polyculture & 60 & 70 & $65 \pm 7.07$ \\
Both & 30 & 18 & $24 \pm 8.49$ \\
\hline $\mathrm{n}=$ sample size & & &
\end{tabular}

Table II. Stocking density (fry/ha) of fish

\begin{tabular}{lccc}
\hline Culture system & $\begin{array}{c}\text { Mymensingh } \\
\mathrm{n}=50\end{array}$ & $\begin{array}{c}\text { Jashore } \\
\mathrm{n}=50\end{array}$ & Average \\
\hline Gulshapolyculture & $191,819 \pm 38614$ & $192,344 \pm 36757$ & $192,081 \pm 37,686$ \\
Shingpolyculture & $197,600 \pm 43090$ & $193,395 \pm 35428$ & $195,497 \pm 39,259$ \\
Koi monoculture & $536,568 \pm 35196$ & $577,559 \pm 66067$ & $557,063 \pm 50,632$ \\
\hline $\mathrm{n}=$ sample size & & &
\end{tabular}

$\mathrm{n}=$ sample size

Production of fish: Fish production varied considerably with both culture system and areas (TableIII). Production of gulsha was higher in Mymensingh (4245 kg/ha) than Jashore (4039 $\mathrm{kg} / \mathrm{ha}$ ) in polyculture system. Production of shing was also found higher in Mymensingh (4510 $\mathrm{kg} / \mathrm{ha}$ ) than Jashore district $(4107 \mathrm{~kg} / \mathrm{ha})$ in polyculture system and production of koi also higher in Mymensingh region than Jashore region (Table III).

Table III. Species wise production $(\mathrm{kg} / \mathrm{ha})$

\begin{tabular}{lccc}
\hline Species & Mymensingh & Jashore & Average \\
\hline Gulsha & $4245 \pm 619$ & $4039 \pm 554$ & $4142 \pm 586$ \\
Shing & $4510 \pm 594$ & $4107 \pm 585$ & $4309 \pm 590$ \\
Koi & $35815 \pm 2793$ & $34355 \pm 2488$ & $35085 \pm 2640$ \\
\hline
\end{tabular}

Fish disease issues: Farmers reported a number of diseases and conditions which they could recognized clinically.However, they never confirmed theses in laboratory for definitive diagnosis. Clinical signs fish were obvious and quite similar in both areas. The most common generalclinical signs of diseases found in the study areas were deep hemorrhage (75\%) followed by ulcerative lesion (69\%), fin rot (52\%), whitish appearance of fish (38\%), extended belly (33\%) and pop-eyed (30\%) (Fig. 1). Clinical signs of diseased gulsha included deep hemorrhagic ulcerative lesion in caudal region and middle part of the body, ventral reddening, appearance of whitish colour to entire body surface (Fig. 2a and $2 \mathrm{~b}$ ). Clinical signs started to appear when the fish become 25-30 g in size. Major clinical 
signs of koi included exophthalmia, deep ulcerative lesion, massive hemorrhages and tail and fin rot (Fig. 2c and 2d). For shing, the noticeable clinical signs were reddish ulcerative lesion and tail rot and erosion (Fig. 2e and 2f). Fish of all sizes were reported to be affected by disease with sometimes total loss entire stock.

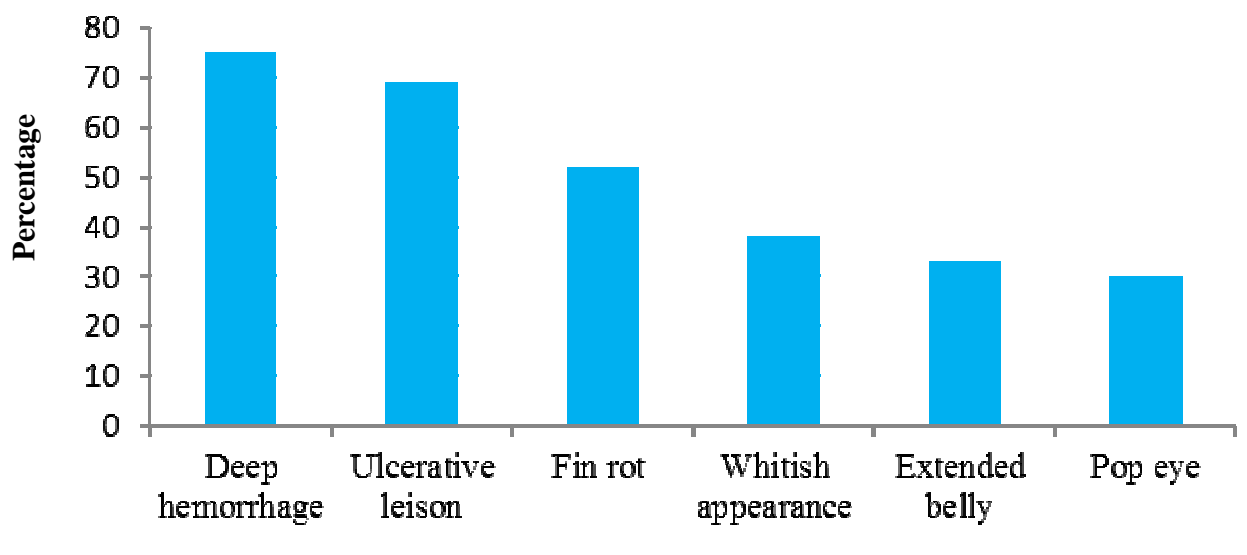

Clinical signs

Fig. 1. Clinical signs of diseased fish (\%) in the study areas.

Overall average mortality of disease affected fish were $36.71 \%, 43.33 \%$ and $38.76 \%$ for gulsha, shing and koi respectively (Table IV). Farmers were asked in which season of the year they noticed these diseases. Farmers in Mymensingh district reported that diseases mainly occurred in winter season, some of the farmers reported that disease occurred between end of winter and starting of spring whereas in Jashore district farmers mentioned that disease mainly occurred in rainy season, some farmers reported that cloudy weather and heavy drought cause disease. Most of the farmers reported that diseases in their ponds occurred once in a year. Some of the farmers reported that disease occurred their farms 2-3 times in a year.

Table IV. Mortality of fish due to disease (\%)

\begin{tabular}{lccc}
\hline Species & $\begin{array}{c}\text { Mymensingh } \\
\mathrm{n}=50\end{array}$ & $\begin{array}{c}\text { Jashore } \\
\mathrm{n}=50\end{array}$ & Average \\
\hline Gulsha & $41 \pm 14$ & $31 \pm 12$ & $36 \pm 13$ \\
Shing & $50 \pm 18$ & $35 \pm 18$ & $43 \pm 18$ \\
Koi & $33 \pm 13$ & $44 \pm 13$ & $38 \pm 13$ \\
\hline
\end{tabular}

Constraints of fish health management: Generally, affected farmers took advice from other experienced farmers for fish health management and applied a number traditional and commercial drugs and chemicals singly or in combination. This identified a number of fish health management problems which could be categorized as general problem, resource problem and problem with the use and application of drugs. 

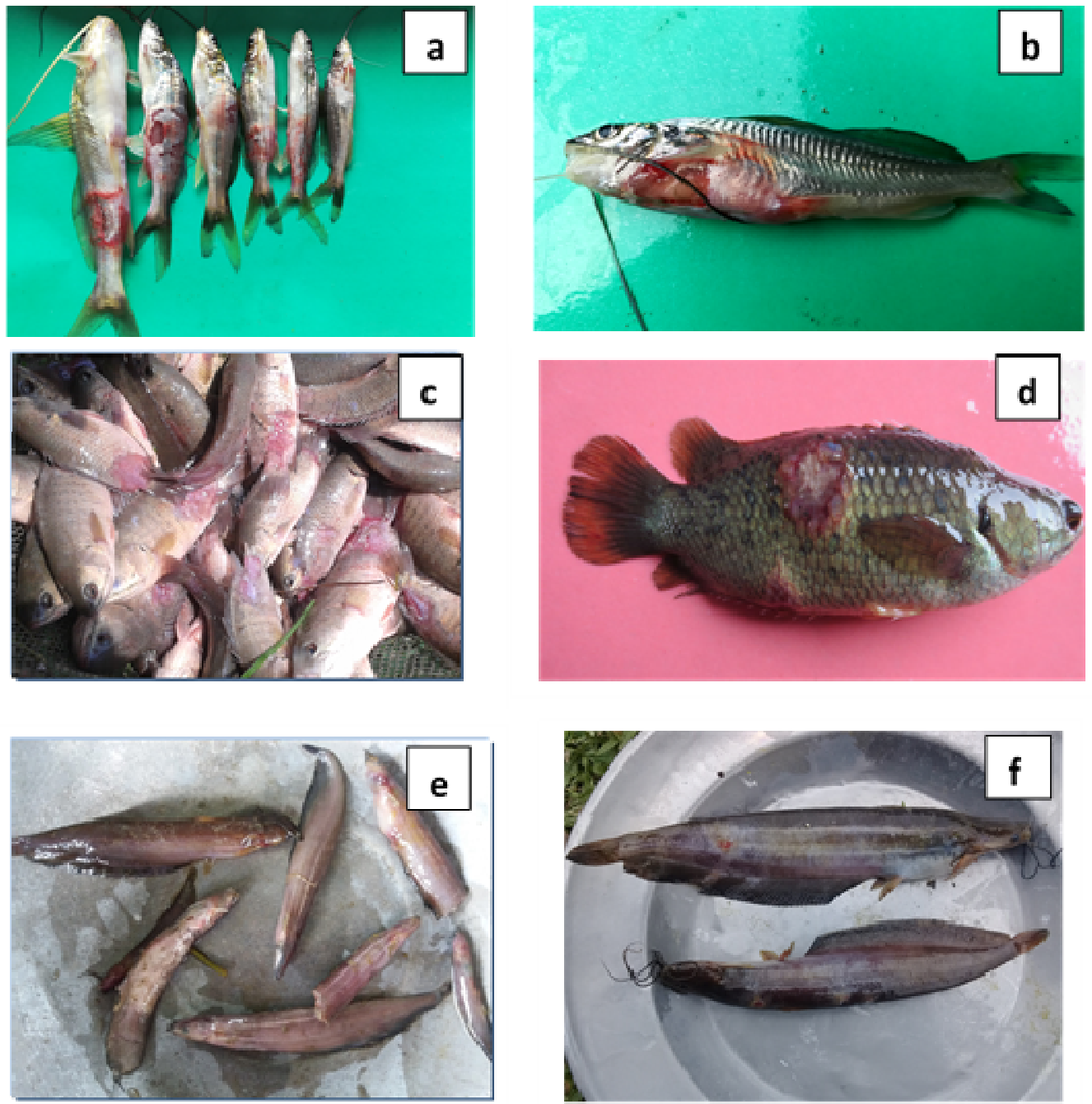

Fig. 2. Clinical signs of diseased fishes (a) and (b) Gulsha with deep haemorrhagic and whitish lesions; (c) and (d) Deep hemorrhagic ulceration of koi; (e) and (f) Shing with loss of tail and whitish lesion.

General problem: General health management problem included lack of farmers' knowledge, disease diagnosis problem, lack of knowledge of application of medicine, problem of dose calculation of drugs and lack of qualified health adviser (Fig. 3). Average $57 \%$ farmers had poor knowledge or lack of knowledge about fish health and diseases. This was found higher in Jashore (64\%) than in Mymensingh (50\%) (Fig. 3). 
Proper diagnosis of diseases was found as an important problem and average $85 \%$ had such problem in both of the study areas. They usually got help from people of different feed or medicine companies for disease diagnosis. This problem was much acute in Jashore (90\%) than Mymensingh (80\%) (Fig. 3). Majority of the farmers (81\%) also had poor or lack of knowledge about application of medicine. Also, it was found that average $82 \%$ farmer had problem with calculation of doses of medicine before application. Use of extra-label unapproved drugs was found common in the study areas. Lack of qualified health adviser was identified another big problem in the study areas. Average $75 \%$ farmers reported that there was a lack of qualified health advisor in their areas. Finally, financial problem was noticed another problem faced by the farmers and average $45 \%$ farmers reported that they faced with financial problem during health management. In Mymensingh region, $30 \%$ farmers had financial problem whereas in Jashore region $60 \%$ farmers had financial problem.

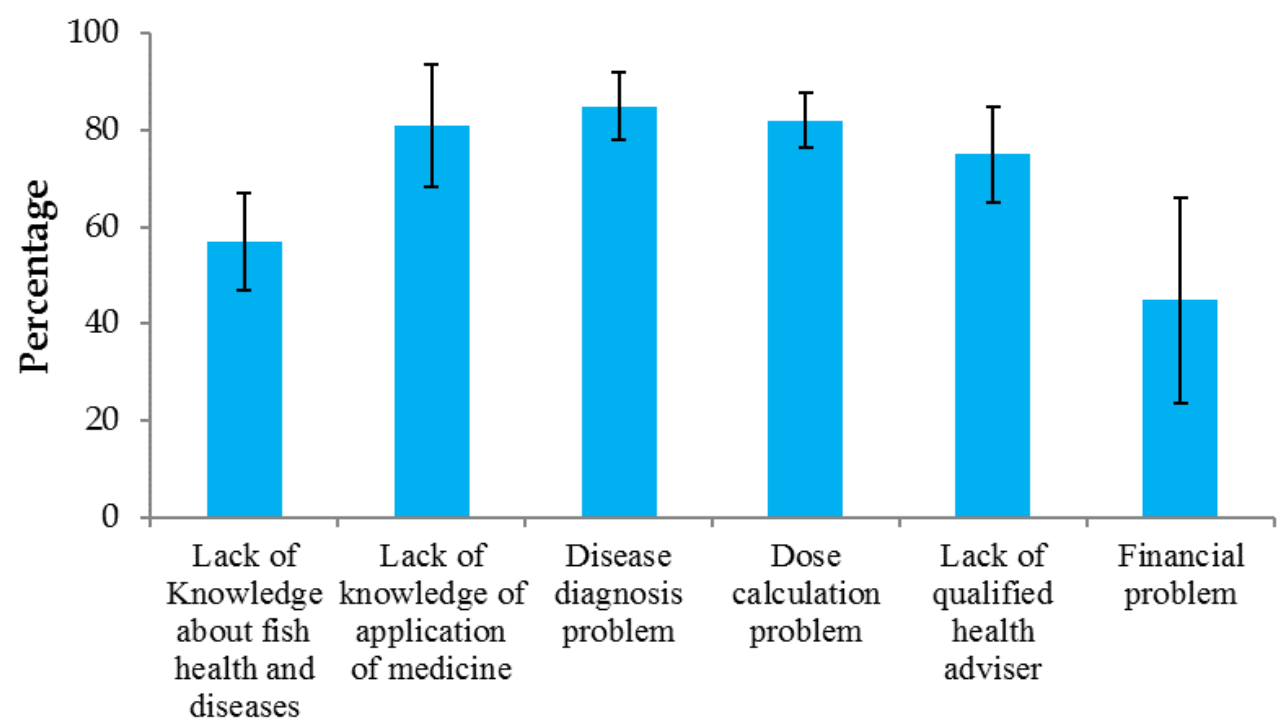

\section{General problems}

Fig. 3. General fish health management problems.

Resource problems: The present study identified some technical constraints faced by farmers during health management of fish which included lack of good quality seed, lack of quality water, lack of quality feed and lack of good quality medicine (Fig.4). Among these, lack of good quality medicine was identified as the major one where average $85 \%$ farmers reported this problem. 


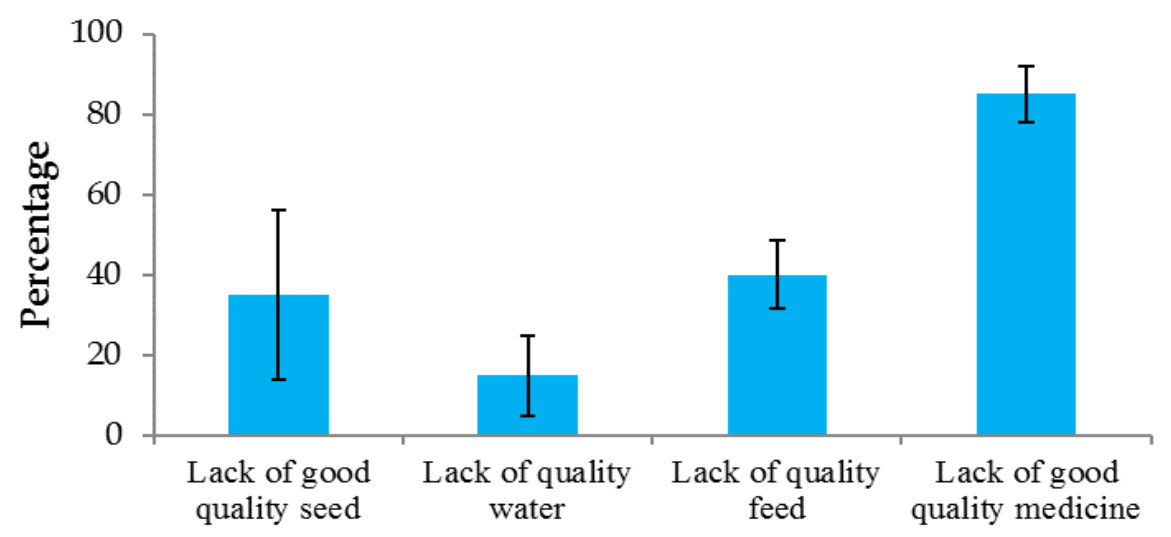

Resource problems

Fig. 4. Resource problem of health management of high value fish.

Problem with the use and application of medicines: Farmers faced a number of problems with the use and application of medicines which were ineffectiveness (78\%) and indiscriminate use of drugs $(75 \%)$, presence of too many drugs in the market $(87 \%)$ and they felt huge pressure from medicine companies to use their drugs (88\%) (Table V). Indiscriminate use of medicine was found higher in Mymensingh (90\%) than Jashore (60\%). Farmers in Jashore felt more pressure (96\%) from medicine companies than Mymensingh (80\%) (Table V).

Table V. Problem with use and application of drugs (\%)

\begin{tabular}{lccc}
\hline Problems & $\begin{array}{c}\text { Mymensingh } \\
\mathrm{n}=50\end{array}$ & $\begin{array}{c}\text { Jashore } \\
\mathrm{n}=50\end{array}$ & Mean $\pm \mathrm{SD}$ \\
\hline Ineffectiveness of drugs & 70 & 86 & $78 \pm 11$ \\
Indiscriminate use of medicine & 90 & 60 & $75 \pm 21$ \\
Too many medicine & 80 & 94 & $87 \pm 9$. \\
Pressure from medicine companies & 80 & 96 & $88 \pm 11$ \\
\hline
\end{tabular}

$\mathrm{n}=$ sample size

General fish farming problem: The present study also identified some general problems of high value fish farming in the study areas which included low fish price (100\%), high feed cost (95\%), high land tax (88\%), fish disease (85\%) and high electricity cost $(85 \%)$. Fish marketing problem was also faced by the farmers $(67 \%)$ (Fig.5).

\section{Discussion}

Fish health management is an important issue in commercial aquaculture. The present study identified health management constraints of commercially cultured high value fishes in Mymensingh and Jashore districts. Though these two districts are the leading freshwater aquaculture producing places in Bangladesh, still farmers suffered from a number of fish health 
management related problems. The major constraints included lack of farmers' understanding about fish health and disease issues, disease diagnosis problem, lack of knowledge of application of drugs, problems with dose calculation of medicine before application and sever lack of qualified health adviser. Fish disease diagnosis problem (85\%) was the single most important constraints of health management in the study areas. Proper disease diagnosis is very important for treatment and health management. However, no diagnostic laboratory was found in study areas. For this reason farmers did not receive any support for disease diagnosis and they had to rely on medicine company personnel for symptomatic diagnostic advice only.

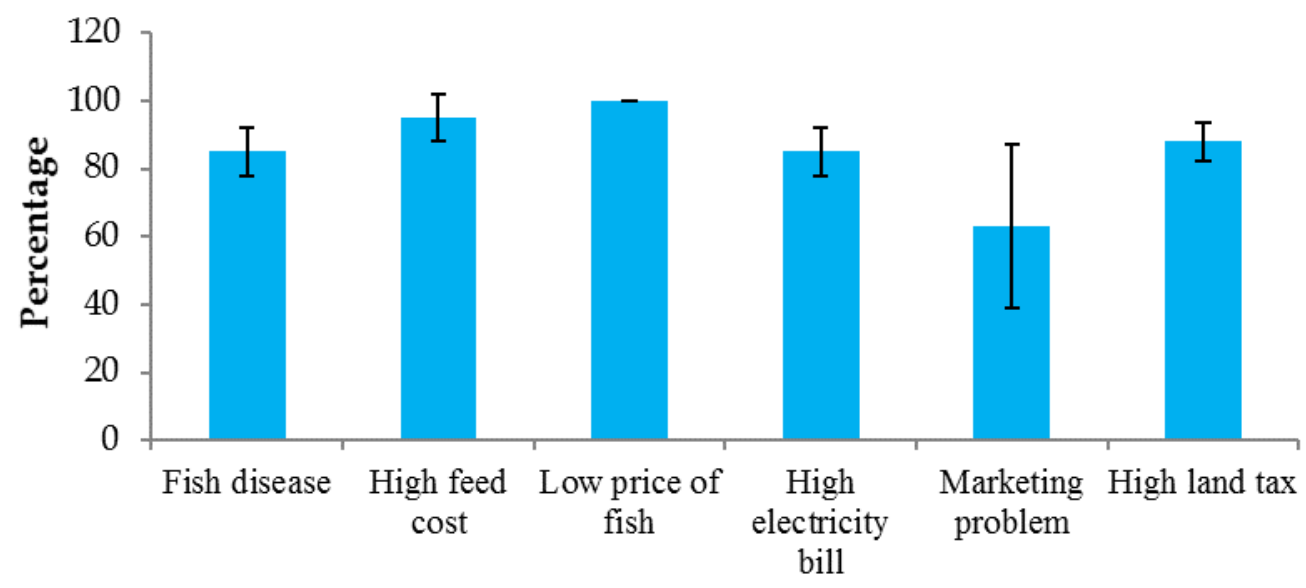

Fish farming problem

Fig. 5. Problems of high value fish farming.

For commercial aquaculture farmers have to have clear understanding about disease and health of fish stock for their management but in study areas majority of the farmers had lack of knowledge about fish health and diseases. For disease treatment and health management farmers must have clear idea about application of drugs but in study areas farmers did not have clear idea about application of drugs. Also, for proper disease treatment calculation of particular drug is very important for their effective use but it was found that most of the farmers lacked knowledge about this particular issue though they routinely used a number of drugs. Availability of qualified health advisor having adequate knowledge on fish pharmacology and medicine is important to suggest farmers on different aspects of health management. Unfortunately, there were no such person and consequently improper disease diagnosis, indiscriminate use of medicines happened. Miah et al. (2016) reported that poor understandings of farmers about the application of aqua drugs and inadequate withdrawal period were the problems of health management of fish.

From current study it was found some resource problems which were faced by farmers during health management included lack of good quality seed, lack of quality water, lack of quality feed and lack of good quality medicine. Also, farmers faced some 
problems associated with use and application of medicines like their ineffectiveness, indiscriminate use, and presence of too many medicines in marketand pressure from pharmaceutical companies. There was a sever lack of quality medicine in the study areas and the medicines available there was not that effective as reported by the farmers. Most of the medicines used by fish farmers were actually prepared for use in veterinary or poultry but aqua farmers were using as those extra-label. Since there is only limited number of drugs approved in aquaculture, the use of extra-label unapproved drugs is quite common in Bangladesh aquaculture (Jahan 2017, Shorna 2019).

Farmers noticed a number of diseases and conditions which they could recognized clinically. The current studies identified several clinical signs of disease affected gulsha included hemorrhagic ulcerative lesion, appearance of whitish colourand deep ulcer in different parts of body. Marma et al. (2016) noticed that clinical signs of gulsha were scale loss, red spots, and deep dermal ulcer. The most prevalent clinical signs of disease affected shing were whitish colour appeared entire body, red ulcerative lesion and tail rot. Hasan et al. (2013) found that most prevalent clinical signs of shing were haemorrhagic ulcerative lesion and fin rot. From the present study, it was observed major clinical signs of disease affected koi included at first red spot visible at primary stage, then deep ulcer created on the site of red spot and fin, tail and operculum will be ulcerated and disease can be occurred at any stage. Paul et al. (2016) mentioned that different clinical symptoms like scale loss, dermal lesion, ulcer and loss of caudal fin were noticed in koi. The present study identified some general problems associated with farming of high value fish which were included fish disease, high feed cost, and low price of fish, high electricity bill, marketing problem and high land tax. Almost all farmers reported that low price of fish was the main problems of fish farming. Similar types of pond farming constraints were found by some authors (Jahan et al. 2015; Shamsuzzaman et al. 2017; Das et al. 2018). In conclusion, high value fishes are promising aquaculture species in Bangladesh. Present study revealed that health management problem of high value fishes is a great concerned for their sustainable culture and these problems should be minimized. Further studies should focus on the development of strategies for better health management practices of high value fishes.

Acknowledgements: We acknowledge Bangladesh Academy of Sciences for providing financial assistance for this study through BAS-USDA Grant No.FI- 026. We also acknowledge the farmers in the study areas for time and cooperation during questionnaire survey and focus group discussions.

\section{Literature Cited}

Austin, B. and D.A. Austin, 2012. Bacterial fish pathogens: Disease of farmed and wild fish. $5^{\text {th }}$ edition. Springer, $654 \mathrm{p}$.

Bergh, O. 2007. The dual myths of the healthy wild fish and the unhealthy farmed fish. Dis. Aquat. Organ., 75: 159-164.

Bondad-Reantaso, M.G., R.P. Subasinghe, J.R. Arthurb, K. Ogawa, S. Chinabut, R. Adlard,Z. Tan and M. Shariff,2005: Disease and health management in Asian aquaculture. Vet.Parasitol., 132 (3-4): 249-272.

Das, M., M.R. Islam, T. Akter, A. Kawser and M.N. Mondal, 2018. Present status, problems and prospect of fish farming at Gazipur Sadar upazila in Bangladesh. Progress. Agric., 29 (1): 53-63.

DoF, 2019. Fish week compendium. Department of Fisheries, Bangladesh. 


\section{CONSTRAINTS OF HEALTH MANAGEMENT OF HIGH VALUE FISHES}

DoF, 2017. Fishery statistical yearbook of Bangladesh 2016-2017.Fisheries Resources Survey Systems, Department of Fisheries. Dhaka, Bangladesh. 113 p.

FAO, 2020. The state of world fisheries and aquaculture 2020. Sustainability in action. Rome. https://doi.org/10.4060/ca9229en.

Floyd, R.F., 2005. Introduction to fish health management. CIR921, one of a series of the Fisheries and Aquatic Sciences Department, Florida Cooperative Extension Service, Institute of Food and Agricultural Sciences, University of Florida. Original publication date February, 1990. Reviewed July, 2003. Minor revision July, 2005. Visit the EDIS Web Site at http://edis.ifas.ufl.eduhttp://fisheries.tamu.edu/files/2013/09/Introduction-to-Fish-Health Management.pdf

Hasan, M.M., M.A.R. Faruk, I.Z. Anka and M.A.K. Azad, 2013: Investigation on fish health and diseases in rural pond aquaculture in three districts of Bangladesh. J. Bangladesh Agric. Univ., 11(2) 377-384.

Jahan, K.M., M. Ahmed and B. Belton, 2010. The impacts of aquaculture development on food security: lessons from Bangladesh. Aquac.Res., 41(4): 481-595.

Jahan, K.M., B. Belton, H. Ali, G.C. Dhar and I. Ara, 2015. Aquaculture technologies in Bangladesh: An assessment of technical and economic performance and producer behavior. Penang, Malaysia: WorldFish. Program Report: 2015-52.

Jahan, F., 2017. Use of extra-label drugs in commercial aquaculture. MS thesis. Department of Aquaculture, Bangladesh Agricultural University, Mymensingh. 59 p.

Marma, K., S.K. Paul, G.U. Ahmed, A. Habib and M.G. Mustafa, 2016: Study on health condition of catfish (Mystus vittatus) in fish markets of Mymensingh, Bangladesh. Intl. J. Sc. Res., 2(5) 141-146.

Miah, M.I, D.K. Mondal, G.U. Ahmed and M.M. Rahman, 2016. Use of aqua drugs and chemicals in the fish farms of Katiadi, Kishoreganj. Int. J. Multi. Res. Dev., 3(11): 27-31.

Paul, S.K., G.U. Ahmed and M.A.R. Faruk, 2016. Investigation on health conditions of Thai Koi (Anabas testudineus) through clinical and histopathological observations from different farm from Mymensingh Region. J. Aqua. Sci. Res., 5(1) 120-125.

Shamsuzzaman, M.M., M.M. Islamb, N.J. Tania , M.A.A. Mamun , P.P. Barman, and X. Xu, 2017. Fisheries resources of Bangladesh: Present status and future direction. Aquac.. Fish, 2(4): 1-12.

Shorna, H.K., 2019. Use and impact of veterinary drugs and chemicals in fish health management. MS thesis Department of Aquaculture, Bangladesh Agricultural University, Mymensingh. p. 52.

World Bank, 2014. Reducing disease risk in aquaculture. World Bank report number 88257-GLB, June 2014.http://documents1.worldbank.org/curated/en/110681468054563438/pdf/882570REPLACEM00

NAME0Reantaso0Melba.pdf

(Manuscript received 13 October 2020) 